\title{
MEDIA MONITORING AS AN ELEMENT OF STRATEGIC BUSINESS MANAGEMENT
}

\author{
Monika Fill', Tomasz Fill²
}

\begin{abstract}
Analysis of information published in the media is an important tool. Information that is collected and properly aggregated contributes to the assessment of companies' projects and allows to observe and to evaluate changes occurring in the environment. This article discusses benefits that companies can achieve through professional media monitoring and its products using a practical example. The article presents the company's media findings scope for 2017-2018 and conclusions that can be drawn in the context of recommendations for long-term decisions.
\end{abstract}

Keywords: media, monitoring, business management,

\section{Benefits of regular media monitoring.}

Today's companies undertake a number of analytic efforts, which allows them to gain the knowledge required to support their management processes. Special attention is given to areas such as marketing or public relations because many managers, when determining their next steps in those areas, need to know whether their previous decisions were beneficial. By analysing marketing and public relations activity, they can determine whether the budget was properly planned, whether a plan was successfully implemented and whether the expenses incurred have paid off. This is why companies deploy media monitoring, defined as a process of reading, watching and listening to source content for keywords that appear in media and then aggregating these materials ${ }^{3}$. Media monitoring is being used by more and more entities as it aggregates and provides information about what was published in the media, with a focus on the content (Milivojevic, 2003, p.16). It sheds light on people's feelings and expectations (Gawroński, 2006, p.10). The purposes of media monitoring are clear as they involve obtaining knowledge, but they can also vary. The process itself requires appropriate selection of methods. Monitoring can pursue quantitative or qualitative analysis, for example, by focusing on evaluating news narratives (Gawroński, 2006, p.16). Everything in this area depends on the entity undertaking the study as well as the purpose of the analysis.

Many companies, government agencies, non-profit organisations (e.g. hospitals,

\footnotetext{
$1 \quad$ Monika Fill, e-mail:monika.fill@wp.pl

2 Tomasz Fill, e-mail:tomasz.fill@wp.pl

3 The ultimate media monitoring Buyer's Guide, retrieved from: https://www.cision.com/content/dam/cision/Resources/white-papers/Cision_MediaMonitoringBuyersGuide.pdf
} 
universities, associations etc.) and individuals, e.g. celebrities, use media monitoring as a tool for tracking mentions about themselves in the news media. Some entities monitor media to assess the effect of their publications but also to gather intelligence on their competitors and specific important issues from their organisation's standpoint (Comcowich, 2010, p.3).

Searching for information published in the media is a guarantee of obtaining accurate information that supports certain management processes. It helps you understand your target audience but also, in particular, the information that journalists are seeking. Media monitoring and the associated data analysis support at every step of the way the company's PR efforts, while also assisting with identifying any potential perception crises. Data obtained through media monitoring helps assess the effectiveness of PR efforts and supports rapid response strategies. It provides a database for management processes. Monitoring can include a wide range of traditional and modern media, including specific channels that require outreach to consumers such as news services, message boards, blogs and social media platforms such as Facebook, Twitter or Linkedln.

Media monitoring offers a range of benefits to a business, by enabling it to look at the actions it has taken and how well they were received by the target group. It is helpful in assessing the effectiveness and success of public relations strategies. This article looks at how companies can benefit from professional media monitoring. Its purpose is also to demonstrate how companies can use the products of media monitoring using a specific practical example.

In this article, the entity in question is an infrastructure operator in a telecommunication industry ${ }^{4}$. The Company carried out marketing and advertising efforts, which were covered in media. For the purpose of assessing these results, an analysis of the company's 2017-2018 media coverage was conducted. Media monitoring helped determine what types of the company's efforts (e.g. CSR and employer branding efforts, e.g. "Pracodawca Godny Zaufania" [Trusted Employer], "Zdrowy Pracownik, Zdrowa Firma" [Healthy Employees for Healthy Business]) yielded the most positive coverage. ${ }^{5}$ The analysis described in this article helped compare the results of the positive advertising value equivalency (AVE) generated with the cost of each of the efforts for the company (e.g. expenses incurred in connection with participating in the "Trusted Employer" initiative compared to the AVE generated in October 2018). The analyses presented in this article are the basis and starting point for further continuous media monitoring assessments and understanding trends.

\section{Methodological assumptions underlying the research used in the publication}

The report prepared for the studied company contains the results of media monitoring assessment efforts in the years 2017 and 2018. The key to presenting the findings was to compare the materials in terms of the changes that occurred in the years under analysis. The study was conducted as a desk research, and the material for analysis was derived from articles and media reports selected using the PRESS-SERVICE Media Monitoring platform. As part of the study, 2,022 publications containing The Company'sname were analysed. The vast majority, i.e. 1,303 publications, were published in 2018. In 2017, 719 titles were published. The in-depth analytical efforts were aimed to obtain information concerning the company's perception in the media and to look at the subjects and contexts in which the company's name appeared. The materials were supplemented with a qualitative analysis of media publications. All the materials for the study were obtained from the subject of the study.

\footnotetext{
$4 \quad$ Due to the interests of the company under study, the company's name was anonymized, henceforth "The Company".

$5 \quad$ The analysis was based on desk research carried out at The Company.
} 


\section{Conclusions and recommendations from media monitoring}

Any material obtained through media monitoring in the course of analyses carried out for the purpose of strategic reporting of the business entity in question (The Company SA) was classified and coded to allow for obtaining synthetic information subject to quantitative statistical analysis. The codes helped visualise:

- the total number of publications (in the 2017-2018 time frame),

- the $\mathrm{AVE}^{6}$ of the publications (in the 2017-2018 time frame),

- the number of publications by date (in sequence and a breakdown that enables a yearon-year comparison of the publications),

- subject of the publication in line with codes (general and as comparisons to illustrate the changes that media publications have undergone over time),

- profiles of editors publishing the materials (general and as comparisons to illustrate the number of publications with respect to the editors' profile over time),

- sources, which helped clarify which specific editors are most likely to publish materials about the company (year-on-year comparison),

- number of publications by author (year-on-year).

The year-by-year comparison of the results obtained as a result of the analysis helped capture the changes that have occurred. The period under analysis was crucial in this case. One year's worth of data collected is sufficient to rule out coincidence and randomness. It allows the company to see the entire body of coverage in perspective and, at the same time, draw conclusions and provide recommendations based on the analysis. In the situation at hand, it should be noted that they can be applied in full.

Fig. 1 The number of publications about The Company, in the period 1 Jan 2018-31 Dec 2018, $\mathrm{N}=2022$ (the diagram illustrates the number of publications)

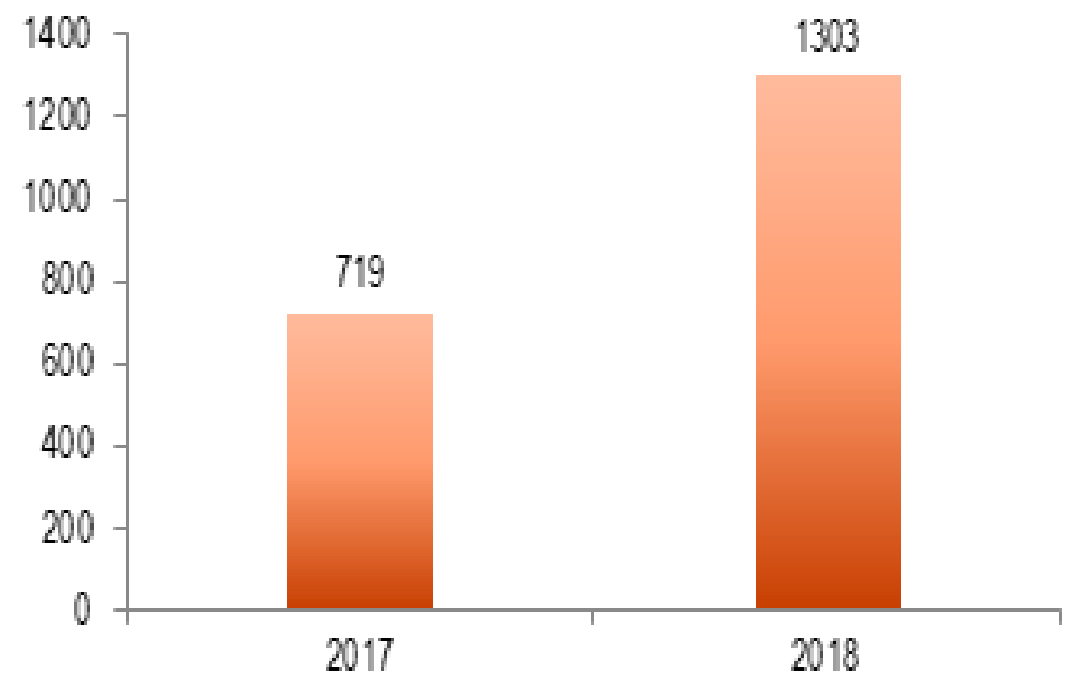

Source: materials obtained from The Company's media monitoring

The conclusions drawn while analysing the media over the course of a year may provide the basis for strategic assessments and long-term decision recommendations. They also help identify periods that were particularly important in the media, which featured a particularly high number of media mentions of the company, and highlight the issues that gained the most media interest.

AVE, i.e. the advertising value equivalency, demonstrates how much it would have cost to broadcast a given message as an advertisement. It is determined on the basis of advertising pricing charts. 
Fig. 2. Number of publications about The Company, 1 Jan 2018-31 Dec 2018, N=2022 (the diagram illustrates the number of publications)

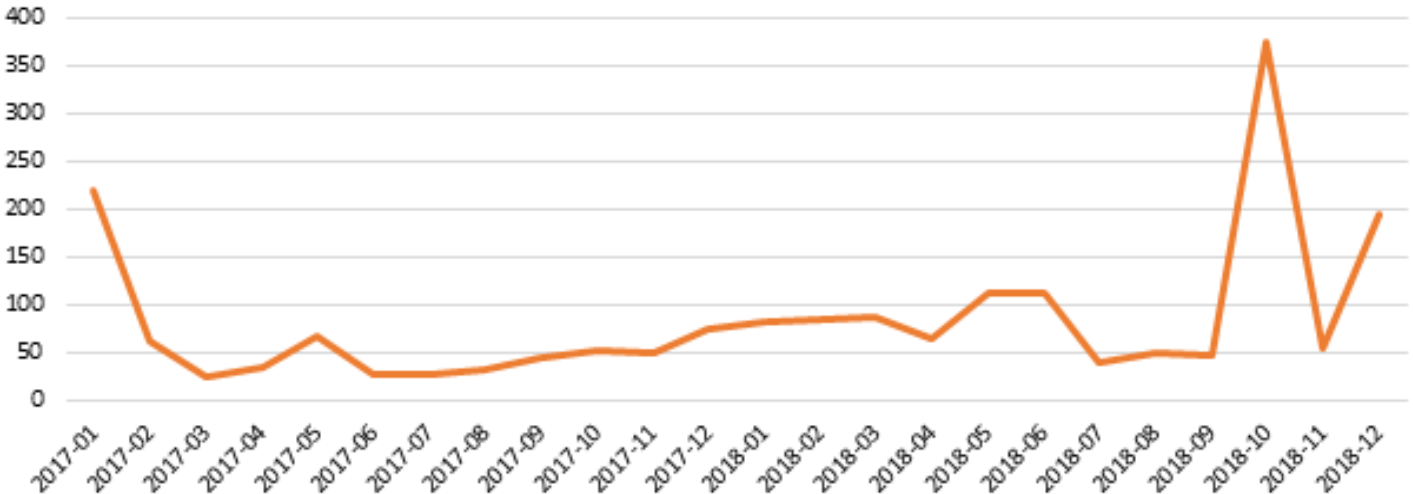

Source: materials obtained from The Company's media monitoring

Monitoring requires a closer look at each area. The content of the mentions of the company in question was analysed in quantitative terms. Each publication was assigned a code that specified whether its coverage was favourable, neutral or unfavourable. As a result of the study, the media coverage analysis demonstrated that the company does not exist in a neutral media environment. It should be noted that the telecommunications industry is deemed to be particularly vulnerable to branding crises. Therefore, the media monitoring effort confirmed that, on one hand, there are clear efforts over which the entity in question has control (branding efforts), and on the other, as in the case of the largest crisis diagnosed through the monitoring and related to allegations raised against the company, there may occur branding crises that are rooted entirely outside the company.

From the point of view of the monitoring conducted in the company, the analytic tools used facilitated an ex-post analysis. They described the events that took place in the period under analysis. They also helped determine the "burden" of unfavourable coverage compared to favourable coverage (it should be noted that, depending on the ratio, it takes between 2 and 5 favourable messages to counteract one unfavourable message). The ex-post analysis may provide crucial information in terms of strategic management and identifying appropriate actions commensurate with what had transpired. However, permanent monitoring tools are needed to help make decisions on a daily basis to respond to situations in real time. This enhances the company's crisis prevention efforts, and if there is a branding crisis, it helps manage messaging.

\section{The significance of media trends analysis}

Analysing trends is a key component of monitoring the company's environment. Trends help us determine whether the efforts undertaken by the company were received as expected by its environment at specific intervals. Such analysis offers us a look at the long-term changes that have occurred in the company's environment. It allows to compare different reference periods. In view of the business entity in question, it should be noted that the extent of changes observed on the basis of the year-on-year comparison indicates that the beginning of 2018 could be viewed as a ground-breaking time, both due to the increasing number of mentions in the media and reversing the unfavourable coverage trend in a more positive direction.

Analysing the situation in question, it is typically the starting point for much more indepth assessments. There are good reasons to track these trends over shorter periods or continuously. This could help decision-making, both in strategic terms with respect to the company's direction, and on a tactical level. Obtaining information from the media helps better connect the cost of branding efforts and their results in the form of media coverage and outreach. This knowledge is critical both to day-to-day management of the 
company and its long-term plans. Without analysing the trends, the company could be surprised by subsequent events, which, due to the fact that they pertain to analysing past events, would not be under the managers' control.

Media monitoring helps with answers to questions formulated in a hypothetical way and allows them to be verified using evidence formula (Milivojevic S., 2003). Applying media monitoring tools in assessing the effects of media relations allows us to identify clear trends of strategic importance for the company in question. One outcome is the consistent increase in publications concerning The Company in the media. Another outcome involves a decrease in unfavourable coverage, with an increase in favourable mentions. Favourable changes in coverage are noticeable in all of the parameters analysed: number of publications, coverage, AVE.

\section{Effect of media relations analysis on management and strategic decisions.}

Using media monitoring analyses provides the company's management with information that is critical in its decision-making. This helps us determine whether making specific branding efforts, e.g. participating in competitions where the company is to be perceived as a good employer, yields the results we want. Using continuous media monitoring allows for more effective, strategic management of the messaging shared by the company, which improves its real-time decision-making.

The effects of monitoring media presence typically go far beyond the question of the company's reputation. Their positive effect manifests itself in company processes and culture. Customer and employee satisfaction also depends on a favourable internal and external image of the company. Therefore, measuring them should become a permanent feature of a business entity's activities.

At this point, it is worth listing the key findings of the media monitoring study conducted by The Company. They are as follows:

- in the periods analysed, there was an increase in the number of favourable mentions and a decrease in unfavourable mentions (growth from 719 in 2017 up to 1,303 in 2018).

Fig. 3. Percentage of publications about The Company by reception in the years 2017-2018, in the period 1 Jan 2018-31 Dec 2018, N=2022 (the diagram illustrates the percentage of publications in the year in question)

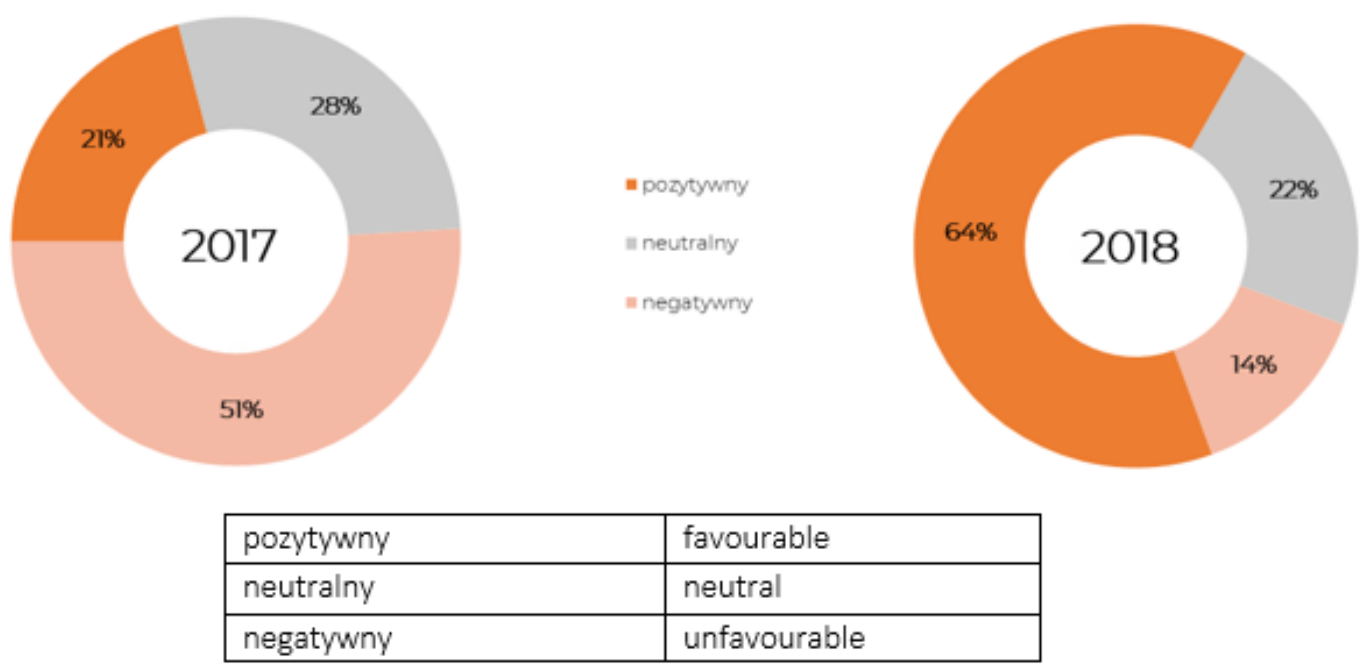

Source: materials obtained from The Company's media monitoring

- AVE decreased from PLN 6.2 million in 2017 to PLN 5.1 million in 2018. It should be noted that AVE for unfavourable coverage decreased from PLN 3.3 million in 2017 to 1.1 
in 2018, while the AVE for favourable coverage increased in the period in question from PLN 1.2 million to PLN 2.5 million.

- it was reported that some of the most important issues shaping perception of The Company during the period under analysis were reports about the company's branding efforts, the MUX-8 issue, telecommunications market regulations and signal disruptions. When we analyse these subjects, it becomes clear that negative issues in 2018 were phased out, while issues generating positive outcome were on the rise.

- it was reported that the greatest number of mentions concerning the entity in question appeared in editorial sections concerning the state, politics, society (general interest) 986 mentions, business and finance -361 mentions, and modern technologies, industry and IT - 331 mentions.

- it was determined that in 2018 the largest number of pieces related to the entity in question was published by www.wirtualnemedia.pl, with 55 items, while the largest advertising value equivalency was generated by Dziennik Gazeta Prawna (PLN 626,000).

- media monitoring also provided the knowledge that helped determine that in 2018 the largest number of favourable publications appeared on www.satkurier.pl - 30 items, while the largest number of unfavourable mentions appeared on www.wirtualnemedia. $\mathrm{pl}-17$ instances.

The above assessments are only some of the conclusions from the overall study. A quantitative approach to the issue identified areas supported by qualitative descriptions in the analysis. The topics were approached in aggregate, to capture the changes and their effect on the company's reputation. The narration was continuous, problem-oriented, in the form of an aggregated source-based summary. The topics under analysis were:

- regulating the telecommunications market,

- public accusations,

- MUX-8-related issues,

- description of branding efforts covered in the media.

This allowed the company to gain extensive knowledge, which, in the long run, can be used in future operations and long-term, strategic efforts.

\section{Conclusion}

Media coverage monitoring conducted both in traditional media and electronic media allows us to assess the company's standing and its changes over time. The recommendations derived by the company from the analyses may involve maintaining and expanding the current scope of favourable media mentions, which may translate into better brand management, mitigating the effect of unfavourable coverage on the brand, effective crisis management or taking appropriate steps in its day-to-day operations.

More and more companies find it necessary to focus not only on monitoring traditional media outlets (press, radio, television), but also turn their attention to social media platforms. These types of decisions, however, must be made based on precise definition of the company's information needs. Only then can the business actually use what may become crucial in its decision-making, i.e. knowledge.

In conclusion, it is also worth reiterating the set of key benefits that business entities derive from multi-faceted analysis of how they are covered in the media. The main advantage is, therefore, the knowledge required to make management decisions. Such information, appropriately aggregated and presented, is helpful in evaluating the phenomena and developments occurring in the company's surroundings, as well as projects covered by the media that pertain to the company in question. The next group of benefits for companies includes:

- the ability to evaluate the context in which the company is being covered in its envi- 
ronment,

- the ability to pick up on some of the most interesting topics concerning the company from the media's point of view that appeal to journalists;

- the ability to evaluate the company's campaign and community involvement,

- the ability to use the materials obtained in the company's future promotional efforts.

Another, equally important benefit of monitoring media coverage is identifying the threats to the company and the effect they may have on its brand. This is yet another reason why this process is and should be deployed by businesses to help build effective campaigns, evaluate their ongoing efforts and protect themselves against PR crises.

\section{REFERENCES:}

COMCOWICH W. J. (2010), Media Monitoring: The complete guide, Cyber alert Inc, White paper.

GAWROŃSKI S., (2006) Media relations. Współpraca dziennikarzy i specjalistów [Cooperation between journalists and experts], Rzeszów, Wydawnictwo Wyższej Szkoły Informatyki i Zarządzania.

MILIVOJEVIC S., (2003) Media Monitoring Manual, London, Media Diversity Institute \& Samizdat.

https://www.cision.com/content/dam/cision/Resources/white-papers/Cision_MediaMonitoringBuyersGuide. pdf 15.03.2019

Raport z badań monitoring mediów operatora infrastruktury w branży telekomunikacyjnej (2017-2018) [Assessment report from monitoring the media coverage of the infrastructure operator in a telecommunication industry (2017-2018)]. 